Conclusion Theory-based evaluations are better equipped to deal with the complexity of introducing multi-component interventions into dynamic health systems. This study suggests that, given a disconnect between responsibility for programme design and implementation, in the absence of systematic communication about the nature of changes and lack of clarity around governance and reporting structures, professionals used their judgment to adopt, implement and adapt interventions to match their priorities and circumstances.

\section{OP61 MEDIA ANALYSIS OF THE TERM 'NANNY STATE' IN UK PRINT AND ONLINE NEWSPAPERS: IMPLICATIONS FOR PUBLIC HEALTH ADVOCACY}

${ }^{1} \mathrm{M}$ Salerno*, ${ }^{2} \mathrm{~L}$ Hyseni, ${ }^{2} \mathrm{H}$ Bickerstaffe, ${ }^{2} \mathrm{~S}$ Capewell, ${ }^{2} \mathrm{~F}$ Lloyd-Williams. ${ }^{1}$ University of Colorado, Colorado School of Public Health, Aurora, USA; ${ }^{2}$ Department of Public Health and Policy, University of Liverpool, Liverpool, UK

\subsection{6/jech-2020-SSMabstracts.60}

Background The term 'Nanny State' has become a more prominent theme in debates on public health and policy across all media platforms. Arguments reflect both valid and less valid concerns about the government's role to protect and promote the public's health. However, there is limited research on how the term is portrayed in the media and how this may influence public opinion and thus political action. To better understand the role of the media in this debate, we therefore analyzed the portrayal and usage of the term 'Nanny State' in UK print and online media articles in relation to food, alcohol and tobacco; in order to identify key messages, and determine the implications for public health policy and advocacy.

Methods Using the Nexis UK Database, we conducted a systematic media analysis of all relevant articles that mentioned 'Nanny State', 'Nanny Statism' or synonyms in the 5.5-year period from January 2014 to June 2019. Articles that met the inclusion criteria were coded in Excel using a pre-piloted, two-part coding framework. We undertook a content analysis to examine and compare the major themes, key messages, prominence and slant, and how Nanny State was argued for or against in the articles.

Results We identified 265 articles published between January 2014 and June 2019 in 13 different mainstream national newspapers and their Sunday counterparts. 186 articles met full inclusion criteria and $79(30 \%)$ were excluded for lack of relevance. Coverage was greatest in 2016, with three peaks coinciding with major public health announcements. Fiscal (20\%) and Other Legislative Measures (26\%) to reduce consumption of harmful commodities including sugar, alcohol and tobacco were the two leading main themes, with Freedom and Autonomy (43\%) and Health Outcomes (47\%) identified as prominent subthemes. The majority of articles (62\%) were negatively slanted towards 'Nanny Statism', and approximately half $(48 \%)$ negatively framed policies and interventions already in place.

Conclusion The recent UK media dialogue using the term 'Nanny State' in relation to food, alcohol and tobacco interventions was consistently pejorative. The term should generally be avoided, or perhaps rephrased as 'The Canny State'. Furthermore, government announcements relating to implementation of public health interventions and policies such as the
'Sugar Tax' can lead to more positive reporting of Nanny State perspectives. Such events may present opportunities for public health advocates to frame positive messages in the media and highlight potential health benefits.

\section{OP62 MINDFULNESS-BASED PROGRAMMES FOR MENTAL HEALTH PROMOTION IN ADULTS IN NON-CLINICAL SETTINGS: A SYSTEMATIC REVIEW AND META-ANALYSIS OF RANDOMISED CONTROLLED TRIALS}

${ }^{1,2}$ J Galante*, ${ }^{1} \mathrm{C}$ Friedrich, ${ }^{1,3} \mathrm{AF}$ Dawson, ${ }^{4} \mathrm{M}$ Modrego-Alarcón, ${ }^{5} \mathrm{P}$ Gebbing, ${ }^{6,7}$ ID Suárez, ${ }^{8} \mathrm{R}$ Gupta, ${ }^{8} \mathrm{~L}$ Dean, ${ }^{9,10} \mathrm{~T}$ Dalgleish, ${ }^{11} \mathrm{IR}$ White, ${ }^{1,2} \mathrm{~PB}$ Jones. ${ }^{1}$ National Institute for Health Research (NIHR) Postdoctoral Fellow, Department of Psychiatry, University of Cambridge, Douglas House, Cambridge, UK; ${ }^{2}$ NIHR Applied Research Collaboration East of England, Cambridge, UK; ${ }^{3}$ Research School of Psychology, The Australian National University, Canberra, Australia; ${ }^{4}$ Primary Care Prevention and Health Promotion Research Network (RedIAPP), Zaragoza, Spain; ${ }^{5}$ Faculty of Social and Behavioural Science, Leiden University, Leiden, The Netherlands; ${ }^{6}$ Department of Educational Science, Faculty of Education, University of Zaragoza, Pedro Cerbuna, Zaragoza, Spain; ${ }^{7}$ Institute of Medical Research Aragón, Spain; ${ }^{8}$ University of Cambridge School of Clinical Medicine, Addenbrooke's Hospital, Cambridge UK; ${ }^{9}$ MRC Cognition and Brain Sciences Unit, University of Cambridge, Cambridge, UK; ${ }^{10}$ Cambridgeshire and Peterborough NHS Foundation Trust, Cambridge, UK; ${ }^{11}$ MRC Clinical Trials Unit at UCL, University College London, London, UK

\subsection{6/jech-2020-SSMabstracts.61}

Background There is an urgent need for mental health promotion strategies in non-clinical contexts. Mindfulness-based programmes (MBPs) are being widely implemented, but evidence is weak with scattered small trials. High-quality systematic reviews and meta-analyses are lacking. We conducted one to assess the effectiveness of non-clinical MBPs for promoting mental health among community adults compared with no or other interventions.

Methods Thirteen databases were searched using keywords and controlled vocabulary in January 2020 for randomised controlled trials examining in-person, expert-defined non-clinical MBPs (PROSPERO CRD42018105213). Primary outcomes were psychological distress, anxiety, depression and mental wellbeing at 1-6 months after programme completion. Secondary outcomes, meta-regression and sensitivity analyses were pre-defined. Two researchers independently selected, extracted and quality-appraised trials using the Cochrane Risk-of-Bias Tool 2.0. Pairwise random-effects meta-analyses were used. Multiple testing was corrected using $p=0.0125$ for significance.

Results 10,703 records were identified, 1,372 required fulltext screening, and 137 trials were included (29 countries, mean sample size $=85$ ). Preliminary main outcome results suggest that compared to no intervention, MBPs improve wellbeing (standardised mean difference $(\mathrm{SMD})=0.21$ [95\%CI $0.07,0.35], \mathrm{p}$-value $=0.003, \mathrm{I} 2=27 \%$ ) and may improve distress (SMD $-0.40 \quad[95 \%$ CI-0.55,-0.24], p-value $<0.001, \quad \mathrm{I} 2=71 \%$ ) and depression $(\mathrm{SMD}=-0.72 \quad[95 \% \mathrm{CI}-1.17,-0.27]$, $\mathrm{p}$ value $=0.002$, $\mathrm{I} 2=91 \%$ ), with no clear support for anxiety $(\mathrm{SMD}=-0.78 \quad$ [95\%CI-1.40,-0.15], $\mathrm{p}$-value=0.015). Against interventions without specific effects on outcomes, MBPs improve depression $(\mathrm{SMD}=-0.40$ [95\%CI-0.67, -0.13], pvalue $=0.003$, $\mathrm{I} 2=22 \%$ ), with no clear support for distress $(\mathrm{SMD}=-0.25 \quad[95 \% \mathrm{CI}-0.47,-0.03], \mathrm{p}$-value $=0.027)$ or anxiety $(\mathrm{SMD}=-0.74$ [95\%CI-1.39,-0.09], p-value $=0.025)$ (no data for wellbeing). Compared with specific-effect interventions, MBPs 